\title{
Development of ORIGEN Libraries for Mixed Oxide (MOX) Fuel Assembly Designs ${ }^{1}$
}

\author{
Ugur Mertyurek ${ }^{\mathrm{a}, *}$ and Ian C. Gauld ${ }^{\mathrm{a}}$ \\ aOak Ridge National Laboratory, P.O. Box 2008, Oak Ridge, TN 37831-6172, USA \\ *Corresponding author. Tel.:+1 865574 5291, mertyureku@ornl.gov (U. Mertyurek), gauldi@ornl.gov (I. C. Gauld)
}

\begin{abstract}
ORIGEN cross section libraries for reactor-grade mixed oxide (MOX) fuel assembly designs have been developed to provide fast and accurate depletion calculations to predict nuclide inventories, radiation sources and thermal decay heat information needed in safety evaluations and safeguards verification measurements of spent nuclear fuel. These ORIGEN libraries are generated using two-dimensional lattice physics assembly models that include enrichment zoning and cross section data based on ENDF/B-VII.0 evaluations. Using the SCALE depletion sequence, burnup-dependent cross sections are created for selected commercial reactor assembly designs and a representative range of reactor operating conditions, fuel enrichments, and fuel burnup. The burnup dependent cross sections are then interpolated to provide problem-dependent cross sections for ORIGEN, avoiding the need for time-consuming lattice physics calculations. The ORIGEN libraries for MOX assembly designs are validated against destructive radiochemical assay measurements of MOX fuel from the MALIBU international experimental program. This program included measurements of MOX fuel from a $15 \times 15$ pressurized water reactor assembly and a $9 \times 9$ boiling water reactor assembly. The ORIGEN MOX libraries are also compared against detailed assembly calculations from the Phase IV-B numerical MOX fuel burnup credit benchmark coordinated by the Nuclear Energy Agency within the Organization for Economic Cooperation and Development. The nuclide compositions calculated by ORIGEN using the MOX libraries are shown to be in good agreement with other physics codes and with experimental data.
\end{abstract}

\footnotetext{
1 This manuscript has been authored by UT-Battelle, LLC, under Contract No. DE-AC05000R22725 with the U.S. Department of Energy. The United States Government retains and the publisher, by accepting the article for publication, acknowledges that the United States Government retains a non-exclusive, paid-up, irrevocable, world-wide license to publish or reproduce the published form of this manuscript, or allow others to do so, for the United States Government purposes. The Department of Energy will provide public access to these results of federally sponsored research in accordance with the DOE Public Access Plan (http://energy.gov/downloads/doe-public-access-plan).
} 


\section{Introduction}

The ORIGEN code (Gauld et al., 2011) is used internationally for the analysis of spent nuclear fuel compositions and radiological characteristics necessary for nuclear facility design and safety analyses. In nuclear safeguards applications, the ORIGEN code has recently been integrated in the Integrated Review and Analysis Package (iRAP) (Smejkal et al., 2014) as a spent fuel analysis module for attended and unattended safeguards data acquisition systems. This module will be used for verification of spent nuclear fuel declarations (Vaccaro et al., 2014). Within iRAP, ORIGEN performs automated calculations of the spent fuel compositions and the expected neutron and gamma ray signals from non-destructive analysis (NDA) measurements of the fuel, based on reactor operator declarations of the fuel assembly design, enrichment, and irradiation and decay history. The accurate analysis of these fuels requires nuclear data libraries containing cross sections that adequately reflect the design, changing fuel compositions, and reactor irradiation conditions.

In Europe, mixed oxide (MOX) fuel is routinely used in commercial reactors, leading to a diverse inventory of spent fuel. This diversity increases the complexity of NDA data analysis due to the wide variation in spent fuel compositions and neutron and gamma radiation sources that correspond to this inventory. The ORIGEN libraries currently implemented in the iRAP system for MOX fuel analysis were developed using simplified assembly models and ENDF/B-V cross section data (Kinsey, 1979).

These MOX libraries for ORIGEN were recently upgraded using improved ENDF/B-VII.0 nuclear data (Chadwick et al., 2006) and two-dimensional (2-D) assembly models capable of explicitly representing the heterogeneity of MOX fuel assembly designs.

Validation of the models and nuclear data is critical for use in safety-related or safeguards applications. In this study, the methods and nuclear data used to generate the MOX libraries were validated against the results of destructive analysis measurements of spent fuel compositions from MOX fuel measured as part of the proprietary MALIBU (Radiochemical Analysis of MOX and UOX [uranium oxide] LWR [light water reactor] Fuels Irradiated to High Burnup) International Experimental Program (Boulanger et al., 2004). The libraries are verified further using detailed lattice physics calculations performed with SCALE (Bowman, 2011) and independent calculations for the Phase IV-B burnup credit code benchmark for MOX fuel benchmark developed by the Organization for Economic Cooperation and Development/ Nuclear Energy Agency (OECD/NEA) (Thorne et al., 2002).

\section{Computational Methodology}

\subsection{ORIGEN Code}

The ORIGEN code, developed at Oak Ridge National Laboratory as part of the SCALE nuclear analysis code system, uses a power series representation of the matrix exponential to solve for the long-lived nuclides in the system and a Bateman solution of linear chains to solve the short-lived nuclides using a secular equilibrium approximation (Gauld et al., 2011). This hybrid solution requires $\sim 20$ ms of computing time to solve a single time step for a system with approximately 2200 nuclides. Calculations using a sufficient number of time steps to accurately solve typical fuel depletion and decay problems can be performed in a few seconds on a single processor.

More recently, an alternate solver based on an implementation of the Matrix Exponential using a Chebyshev Rational Approximation Method (CRAM) developed by the VTT Technical Research Centre of Finland (Pusa and J. Leppänen, 2012) has been implemented in ORIGEN (Isotalo and Wieselquist, 2015). This solver runs with similar execution times as the original ORIGEN method but has higher numerical precision.

The key to fast run times in ORIGEN calculations is using pre-generated libraries of microscopic cross sections. These libraries are generated using detailed lattice physics calculations, for an assembly design, configuration, and range of time-dependent neutronic conditions experienced by the fuel. These cross section libraries are saved and then interpolated to provide problem-dependent data for use by ORIGEN. This procedure is similar to the techniques used in reactor core simulation codes to avoid the need to perform time-consuming lattice physics calculations for fuel depletion analysis while preserving the accuracy.

A typical lattice depletion calculation consists of three steps. First, for a given geometry material map, neutron energy dependent neutron flux maps are calculated by a transport solver. Second, spatially-dependent microscopic cross sections and transition matrices are calculated using the fluxes from the first step. Third, depletion calculations are performed for each unique material region using the cross sections from the second step. In general the first step of the calculations consumes $\sim 90 \%$ of the total execution time. The ORIGEN library interpolation methodology was developed to provide the nuclide data generated at the end of the second step to speed up depletion calculations. The key components of the overall process are described briefly in the following subsections.

For application to safeguards, the ability to simulate the neutron and gamma emission rates in the fuel is essential for identifying isotopes based on their gamma and neutron spectra. ORIGEN uses a library of discrete gamma rays and x-rays developed from ENDF/B-VII.1 (Chadwick et al., 2011). Photon libraries that represent continuous-energy emissions associated with spontaneous fission, ( $\alpha, n)$ reactions, as well as Bremsstrahlung, are included. Neutron sources are calculated in ORIGEN using nuclear data libraries and homogeneous medium algorithms adopted from the SOURCES 4C code (Wilson et al., 2002) developed by Los Alamos National Laboratory. These methods represent the spontaneous fission neutron emission using Watt fission spectrum parameters for 43 actinides; the $(\alpha, n)$ neutron emissions are treated using a slowing down approximation of alpha particles and interaction data for 18 light element isotopes.

\subsection{Nuclear Data}

The neutron cross section libraries used in this work with the SCALE code system are based on ENDF/B-VII.0 data evaluations. These cross sections are used in the neutron transport analysis of the fuel assembly to calculate the neutron flux spectrum in the fuel for cross section weighting. After collapsing them to one-group, as needed by ORIGEN, these cross sections are applied directly in the ORIGEN 
libraries. The ENDF/B-VII.0 data contains cross sections for approximately 460 nuclides. Cross sections for additional nuclides that are required by ORIGEN are obtained from the JEFF-3.0/A special purpose activation library (Sublet et al., 2003), which includes data for 786 target nuclides. All cross sections applied in the ORIGEN libraries are collapsed from 238-group versions of the ENDF/B-VII.0 and JEFF3.0/A libraries.

The fission product yields in the ORIGEN libraries are based on the England and Rider evaluations in ENDF/B-VII.0, and all decay data are based on ENDF/B-VII.1 evaluations.

Spent fuel burnup calculations performed using ORIGEN and SCALE for uranium oxide $\left(\mathrm{UO}_{2}\right)$ fuel types have been extensively validated against destructive assay data for more than 90 spent fuel samples (Ilas et al., 2012). Validation of decay heat analysis has been performed using calorimeter measurements on full-length fuel assemblies measured at the Swedish Central Interim Storage Facility for Spent Nuclear Fuel (Ilas et al., 2014). These validation studies have shown good agreement between measurement data and corresponding ORIGEN-calculated data.

\subsection{Cross Section Generation Methods}

The 2-D depletion sequence TRITON (DeHart and Bowman, 2011) in SCALE is employed to perform burnup simulations of the assembly geometry and specific fuel rod configurations. SCALE version 6.1.2 (SCALE, 2011) was used with the 238-group ENDFB/VII.0based neutron cross section library. This TRITON sequence iteratively couples the 2-D multigroup neutron transport module NEWT (DeHart and Bowman, 2011) and the ORIGEN code. Within this sequence, a first step includes generation of problem-dependent cross section for use with NEWT. The problem-independent multigroup cross sections are corrected with a Bondarenko method using the BONAMI code and by performing point-wise slowing down calculations with the CENTRM/PMC methodology in the resonance region. (Williams, 2011). The resonance-shielded and temperature-corrected microscopic cross sections are then used in NEWT transport calculations to provide a spatially dependent multigroup neutron flux for the assembly geometry. The multigroup neutron flux map, shielded multigroup microscopic cross sections, and transition matrices are then processed by COUPLE, a library management code for ORIGEN, to produce an ORIGEN library that contains one-group neutron cross section data.

The ORIGEN library is then used to deplete or decay material compositions for a user defined power level and time interval. This library can be saved for future use in standalone ORIGEN calculations.

\subsection{Cross Section Interpolation}

The ORIGEN library interpolation methodology is based on the observation that the assembly-averaged cross sections vary smoothly with respect to initial assembly average isotopic content, burnup, and moderator density or void fraction. If a set of representative cross section libraries can be generated as a function of discrete assembly-averaged parameters, accurate cross sections can be generated for intermediate values of the parameters by interpolating the pre-generated libraries.

Cross section libraries are developed for each unique assembly design and for discrete values of those interpolation parameters that have a significant effect on the cross section values. With each design class, interpolation for pressurized water reactor (PWR) designs and $\mathrm{UO}_{2}$ fuel assemblies are based on the assembly average initial enrichment and burnup. Moderator density in PWR assemblies does not show significant variations; therefore, PWR ORIGEN libraries are created using an assembly average moderator density. For boiling water reactor (BWR) assemblies, the interpolation includes the moderator density due to the significant void variations $(0 \%$ to $80 \%)$ that can occur in this type of assembly during irradiation. For MOX fuel, the initial fuel enrichment parameter used for $\mathrm{UO}_{2}$ fuel is replaced by the initial plutonium content of the fuel and the isotopic concentration relative to the total initial plutonium content of ${ }^{239} \mathrm{Pu}$.

Once the ORIGEN libraries are generated for each assembly design and the cross sections are tabulated as a function of the selected assembly parameters, the cross section libraries can be interpolated for any combination of intermediate values for the considered parameters.

\section{Validation of Lattice Depletion Calculations for MOX Fuel Assemblies}

The ORIGEN libraries are generated using the 2-D depletion sequence TRITON. Consequently, ORIGEN calculations using these libraries can only be as accurate as the TRITON depletion calculations used to generate the cross sections. To estimate the accuracy of the TRITON assembly models and nuclear data, the TRITON depletion calculations for MOX fuel assemblies were validated against experimental data from destructive assay of spent fuel assemblies.

MOX cores contain a mix of MOX assemblies and $\mathrm{UO}_{2}$ assemblies. The neighboring $\mathrm{UO}_{2}$ assemblies are usually shuffled at each cycle, and each fuel assembly can have a different burnup, ranging from beginning of life to end of life. Since the neighboring assemblies are not known, vendors and utilities generally use single assembly models for cross section generation. On the other hand, multi-assembly (colorset) models are used for special studies. In order to be consistent with common practice, single assembly models were employed for TRITON isotopic predictions in this paper.

The MALIBU program is an international experimental program coordinated by the Belgian Nuclear Research Center SCK $\cdot C E N$. This program provided high-quality nuclide data for high-burnup MOX fuel samples selected from fuel rods obtained from a $15 \times 15$ PWR assembly irradiated in the Göesgen reactor in Switzerland, and a $9 \times 9$ BWR assembly irradiated in the Gundremmingen reactor in Germany.

The Göesgen reactor fuel measurements included three samples from the same MOX fuel rod, with the highest sample burnup reaching approximately 67 gigawatt-days per metric ton of heavy metal (GWd/tHM). Similarly, the Gundremmingen measurements included two fuel 
samples from the same MOX fuel rod, with a maximum burnup of approximately $80 \mathrm{GWd} / \mathrm{tHM}$.

For an independent cross-check analysis of the measurements, fuel samples from adjacent pellets in the same fuel rod were measured, by three different laboratories: the SCK $\cdot \mathrm{CEN}$ in Belgium, the Paul Scherrer Institute (PSI) in Switzerland, and the French CEA laboratories in Cadarache. Based on the multiple laboratory measurements, recommended nuclide concentrations were reported, with low measurement uncertainties, for 19 actinides and 34 fission products.

\subsection{Göesgen $15 \times 15$ PWR MOX Assembly}

The Göesgen MOX assembly is a $15 \times 15$ lattice PWR assembly containing fuel rods with three different plutonium enrichment zones. The enrichments vary from 2.5 to $5.5 \mathrm{wt} \%$ in fissile plutonium ( $\mathrm{Pu}_{\text {fiss }}$ ). The Pu vector in all MOX fuel rods includes $\sim 60 \mathrm{wt} \%{ }^{239} \mathrm{Pu}$. The MOX assembly was irradiated for four reactor cycles, with the measured fuel rod reaching a high burnup of $67 \mathrm{GWd} / \mathrm{tHM}$. One of the fuel samples, identified as GGM1, was sectioned to allow different laboratories to perform independent measurements for the purposes of cross check analysis. The recommended nuclide compositions for GGM1 were determined from the combined measurements performed by $\mathrm{SCK} \cdot \mathrm{CEN}$, PSI, and CEA

The Göesgen MOX assembly configuration and measured rod location is shown in the 2-D assembly model in Fig. 1. This assembly included 16 guide tubes that did not contain fuel. The measured rod was obtained from the high enrichment zone of the assembly that had $\sim 5.5$ wt $\%$ Pu$_{\text {fiss. }}$.

Comparison of the calculated-to-measured nuclide contents for the GGM1 sample is presented in Fig. 2. There is generally good agreement observed for the measured actinides and fission products, with many calculated results being within 5\% of the measured concentrations. The calculated-to-measured ratios for the major and minor actinides are consistent with the VESTA Monte Carlo depletion code results (Boulanger et al., 2004). The fission product concentrations also agree within 1-2\% between the two codes.

The effects of $\mathrm{UO}_{2}$ neighbor assemblies on isotopic predictions of the Göesgen measurements were also investigated. The Göesgen assembly model was surrounded by $4 \%$ initial enrichment $\mathrm{UO}_{2}$ assemblies with a burnup of $35 \mathrm{GWd} / \mathrm{tHM}$ to simulate the neighbor assemblies for all cycles in the model. The multi-assembly model has a minor impact on most isotopic predictions. The relative difference between the measurement and the predictions increase $\sim 2 \%$ for ${ }^{244} \mathrm{Cm}$. However, the isotopic predictions of ${ }^{239} \mathrm{Pu},{ }^{237} \mathrm{~Np},{ }^{235} \mathrm{U},{ }^{241} \mathrm{Am},{ }^{149} \mathrm{Sm}$ and ${ }^{154} \mathrm{Eu}$ isotopes are improved.

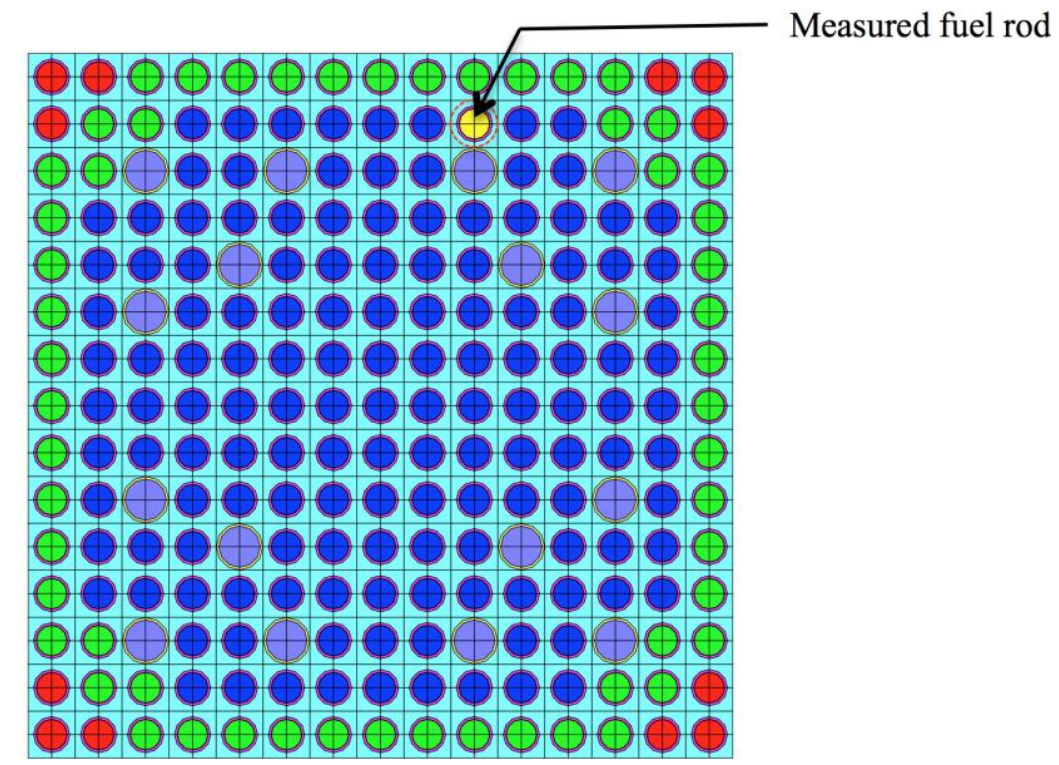

Fig. 1. Göesgen $15 \times 15$ PWR MOX assembly model showing the 16 guide tubes and three plutonium enrichment zones.

\subsection{Gundremmingen $9 \times 9$ BWR MOX Assembly}

The Gundremmingen MOX assembly is a $9 \times 9$ lattice design BWR assembly with a single central non-fuelled water rod. The assembly includes 12 gadolinium-bearing fuel rods and five different plutonium enrichment zones ranging from $1.1 \% \mathrm{Pu}$ fiss to $5.5 \% \mathrm{Pufiss}$. All MOX fuel rods have a plutonium vector with approximately $60 \%{ }^{239} \mathrm{Pu}$. The assembly was irradiated in the reactor for six consecutive cycles, with the measured rod achieving a peak burnup of $\sim 80 \mathrm{GWd} / \mathrm{tHM}$. The measured fuel rod was sectioned to provide three different samples from three different axial elevations along the rod. These samples, identified as GRM1, GRM2, and GRM3, had burnups of 80, 74.4, and 52 $\mathrm{GWd} / \mathrm{tHM}$, respectively. The measured rod was obtained from the inner region of the assembly, with the highest initial Pu content of $\sim 5.5$ 


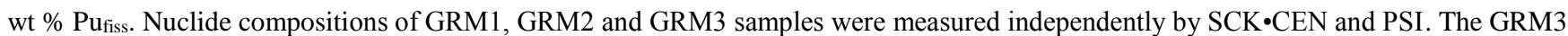
sample specimens measured by the two laboratories were considered as two unique (different) samples because GRM3 was located near the top end of the fuel rod in an area of a large burnup gradient. The GRM3 results were therefore reported as two different sample results (GRM3/1 and GRM3/2) due to the significant burnup differences.

Figure 3 shows the Gundremmingen MOX fuel assembly model configuration and the location of the measured fuel rod in the 2-D depletion model. The depletion model included the local axial moderator void at the elevation of the measured sample. Comparisons of the calculated nuclide concentrations for the GRM1, GRM2, and GRM3/1 samples with measurements are presented in Fig. 4.

Good agreement is observed between the calculations and measurements for all three samples over the range of sample burnups, even though the samples achieved a very high burnup that would exceed values typically experienced in normal operations. The results for all major and minor actinides are consistent with previously published comparisons using MVP-BURN with ENDF/B-VII.0 library (Matsuoka and Ito, 2010).

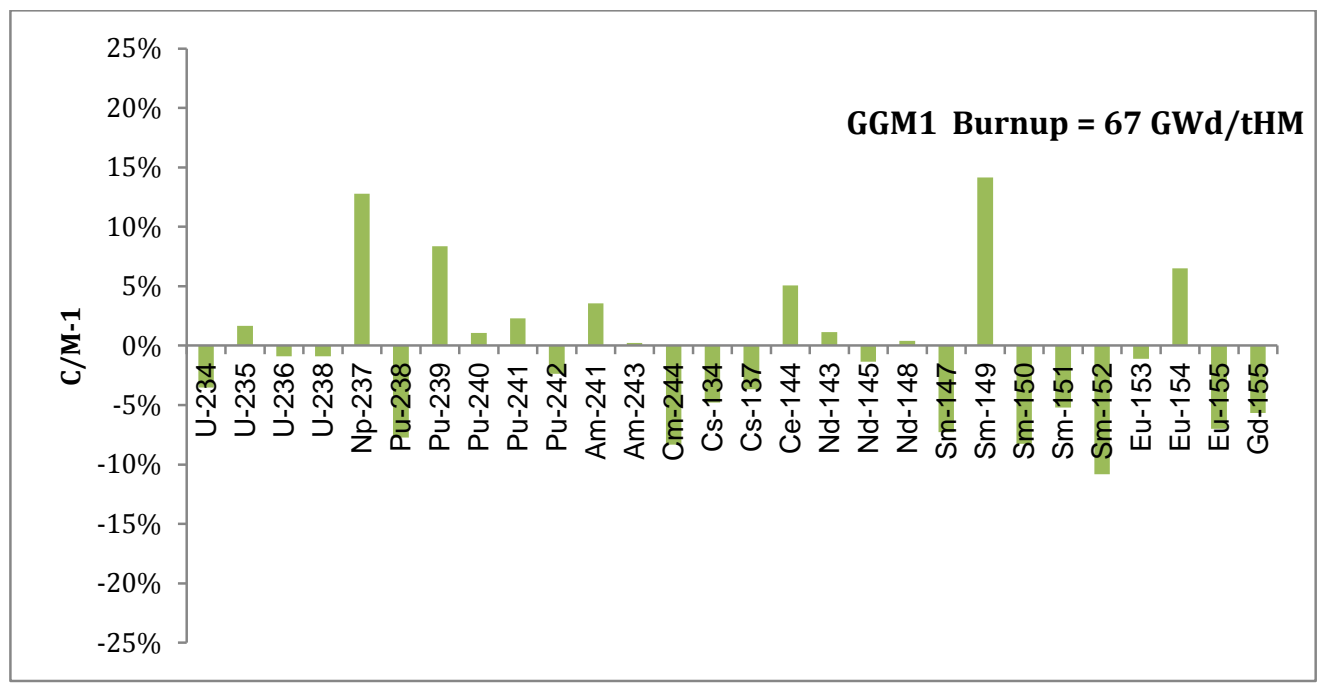

Fig. 2. Göesgen GGM1 sample validation results showing percent difference between the calculated (C) and measured (M) nuclide content.

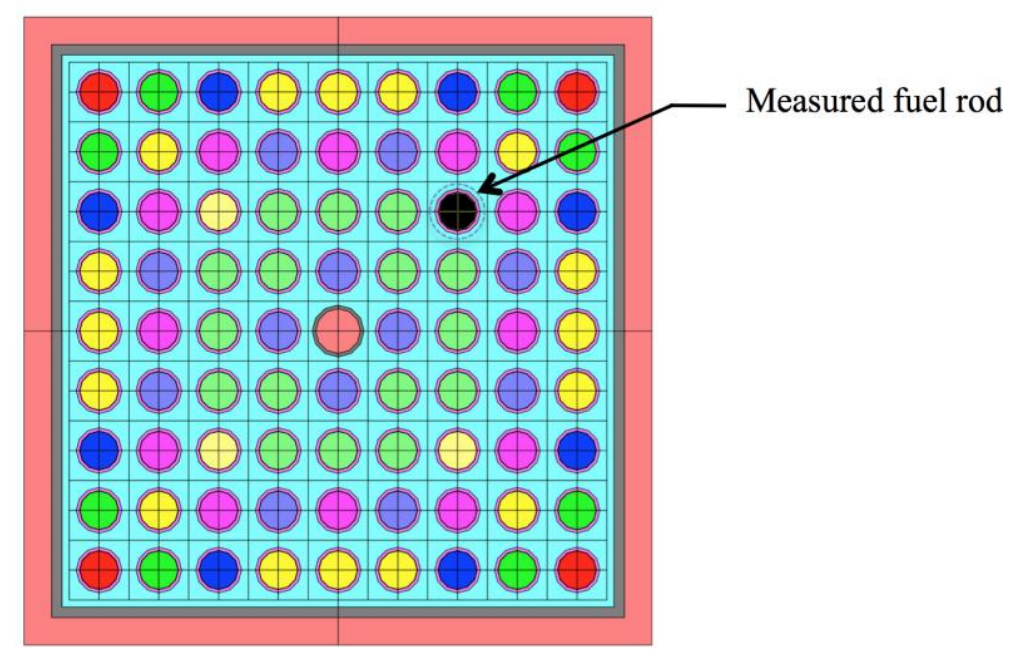

Fig. 3. Gundremmingen $9 \times 9$ BWR MOX assembly model showing the central water rod and five plutonium enrichment zones. 


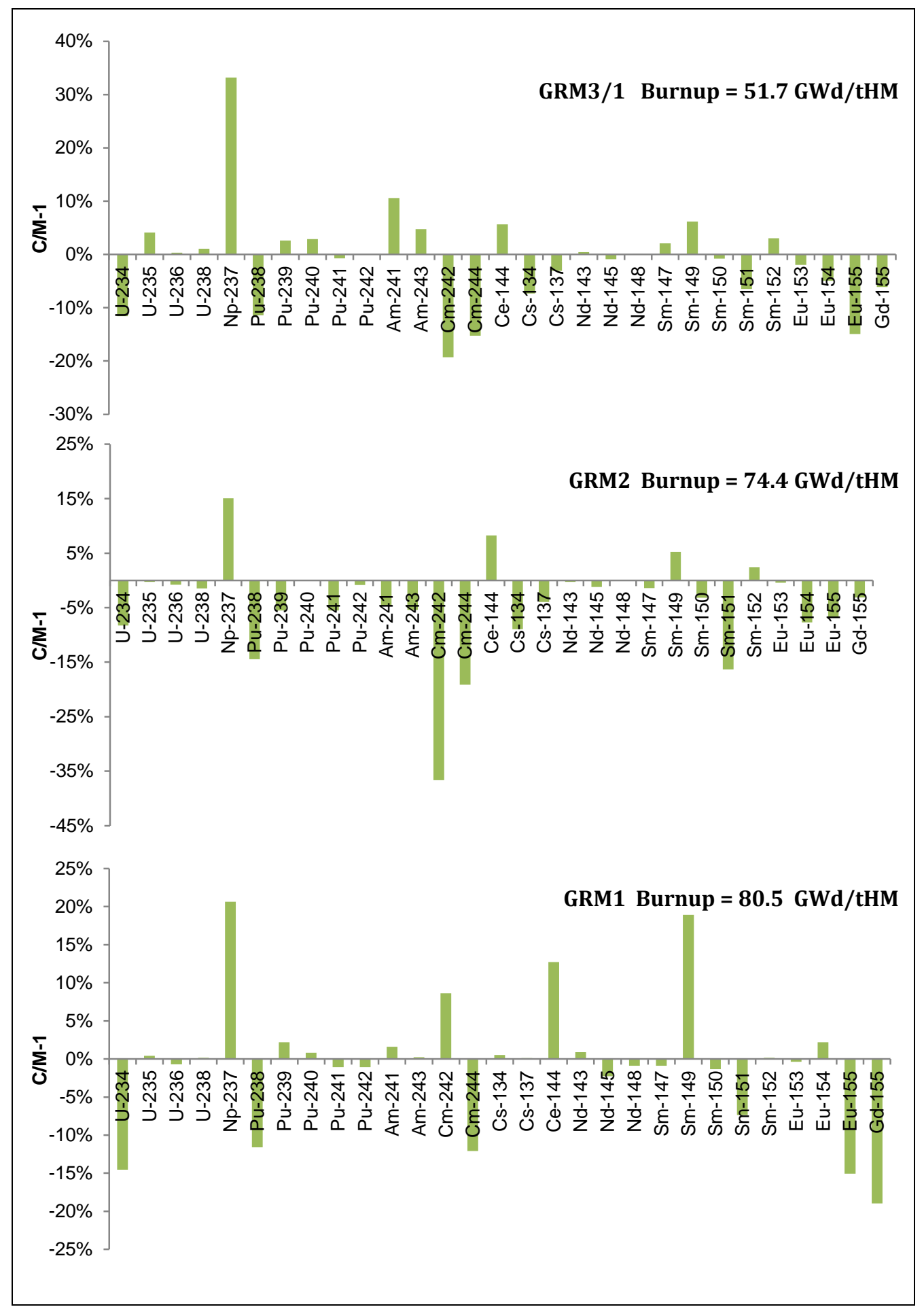

Fig. 4. Gundremmingen GRM1, GRM2, GRM3/1 samples isotopic comparisons. 


\section{MOX Library Generation}

In order to generate MOX libraries that are accurate and representative of current MOX assemblies, it is important that the libraries be generated using neutronic conditions representative of actual operations and that the assembly models reflect typical designs and fuel rod configurations. Geometry, dimensions, plutonium content, and enrichment zoning are main parameters that affect the neutronic conditions in an assembly and therefore the transmutation cross sections.

The assembly design characteristics are easily captured in specific ORIGEN libraries by modeling the geometry, which is relatively well known. The assembly-average plutonium vector and plutonium content can be simulated over the range of expected values used in commercial reactors. However, the plutonium content in MOX fuel rods is non-uniform, and different assemblies can exhibit significant spatial variability in terms of the $\mathrm{Pu}_{\text {fiss }}$ enrichment range, the number of different enrichment zones, and the configuration of different enrichment rods in the assembly. In addition, many modern assemblies make routine use of gadolinium-uranium fuel rods. The number of rods and the gadolinium content vary for each assembly. Because every possible configuration cannot be simulated in advance, and because these configurations are generally proprietary to the fuel vendor, typical configurations are identified from the literature to provide reasonable physics representations of the assemblies for the purposes of generating the MOX assembly cross section libraries.

\subsection{MOX Assembly Models}

Finding a representative fuel rod distribution is a challenging task for some reactor and fuel types due to limited publicly available information. In general, BWR assembly fuel enrichment distributions show more variability compared to PWR assembly designs. Because of many operational factors, such as moderator density variations, use of burnable absorbers, and exposure to control blades, different fuel enrichments are used in different regions (so-called enrichment zones of the fuel assemblies) to maintain adequate thermal limits. The MOX fuel assemblies in both BWRs and PWRs use fuel rod zoning to limit the neutron flux gradient radially across the assembly. In general, BWR MOX fuel assemblies have twice as many zones as PWR MOX assemblies.

The ORIGEN library interpolation procedure for MOX libraries (Gauld, 2003) employs assembly-average total plutonium and the ${ }^{239} \mathrm{Pu}$ isotopic concentration to specify the initial isotopic distribution in the fuel assembly used for cross section interpolation. However, it is not possible to capture every zoning combination with a practical number of pre-generated ORIGEN MOX libraries. Also considering that the enrichment zone patterns change with reactor type, assembly type, and the location inside the reactor core, it is challenging to generate representative zoning patterns. However, if a limited number of representative zoning patterns can be identified, it is possible to characterize the change in the cross sections as a function of these patterns.

Available MOX fuel assembly designs were investigated to identify representative MOX zoning patterns. Although the majority of MOX assembly designs are proprietary and usually not available, a significant number of assembly designs were identified in open literature (Ilas et al., 2006; IAEA, 2000; Misu et al., 2000; Yamamoto, 2009; O'Connor, 2003; Slavickas et al., 2014; Gauld, 2003).

MOX fuel isotopic compositions are usually defined in terms of fissile plutonium $\left(\mathrm{Pu}_{\text {fiss }}\right)$ and total plutonium $\left(\mathrm{Pu}_{\mathrm{tot}}\right)$ weight percents. Definitions for $\mathrm{Pu}_{\text {fiss }}$ and $\mathrm{Pu}_{\text {tot }}$ are given in Eq. 1 and Eq. 2. If the plutonium isotopic vector is assumed constant in an assembly, then $\mathrm{Pu}$ fiss or $\mathrm{Pu}$ tot is sufficient to describe the isotopic composition.

$$
\begin{aligned}
& \mathrm{w} / \mathrm{o} \mathrm{Pu}_{\mathrm{fiss}}=\frac{{ }^{239} \mathrm{Pu}+{ }^{241} \mathrm{Pu}}{\mathrm{Pu}_{t o t}+\mathrm{U}_{\text {tot }}} \times 100 \\
& \mathrm{w} / \mathrm{o} \mathrm{Pu}_{\text {total }}=\frac{\mathrm{Pu}_{t o t}}{\mathrm{Pu}_{\text {tot }}+\mathrm{U}_{\text {tot }}} \times 100
\end{aligned}
$$

Figures 5 through 11 show the variations in zoning patterns identified in the reviewed MOX fuel assembly designs. In these figures, the plutonium enrichment zoning pattern is shown by labeling the fuel rods 1 through 6 , with rod label 1 corresponding to the highest Putot content and rod label 6 corresponding to the lowest $\mathrm{Pu}_{\text {tot }}$ content. The actual enrichment values are provided in the literature but are not listed here; rather, the figures are intended to illustrate trends and typical patterns. The figures also show the location of non-fuel PWR assembly guide tubes and BWR water rods or channels $(\mathrm{W})$ and locations of gadolinia rods $(\mathrm{Gd})$. The general pattern in the location of different $\mathrm{Pu}_{\mathrm{tot}}$ content is clear from the figures. 


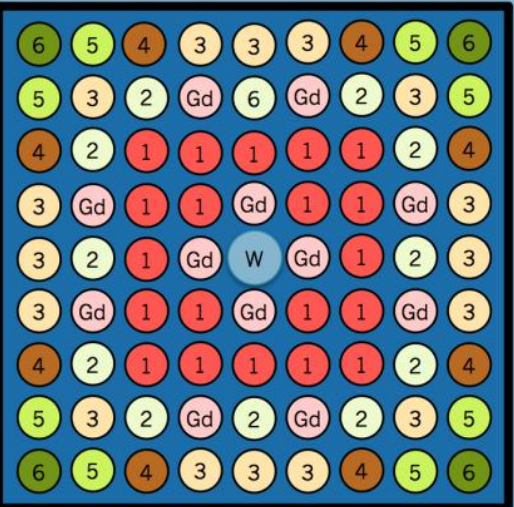

Fig. 5. BWR $9 \times 9-1$ MOX fuel assembly design showing enrichment zoning pattern, water rod flow channel, and outer channel water moderator.

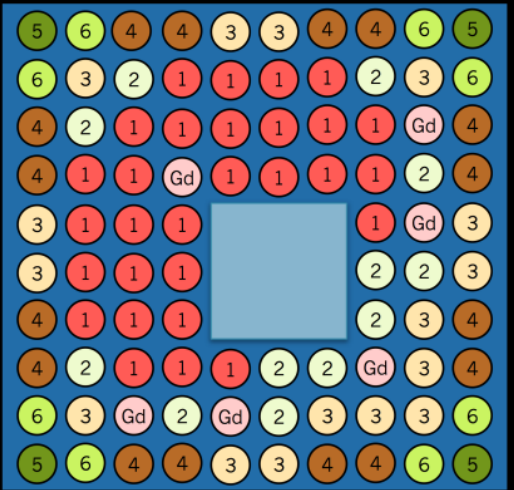

Fig. 6. BWR Atrium $10(10 \times 10)$ MOX fuel assembly design showing enrichment zoning pattern, square inner flow channel, and outer channel water moderator.

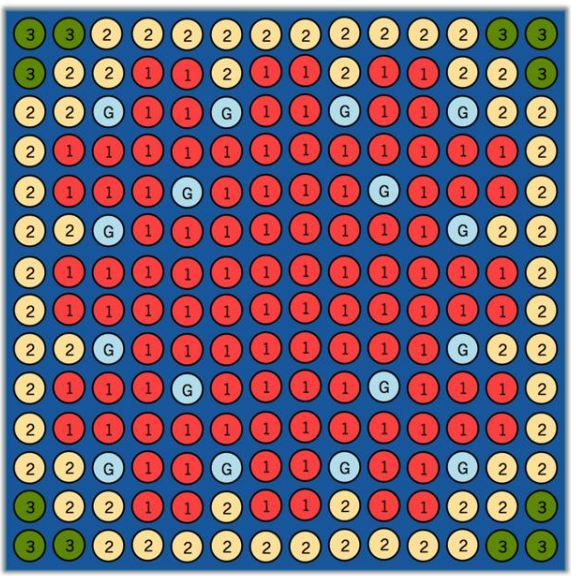

Fig. 7. PWR $14 \times 14$ MOX fuel assembly design. 


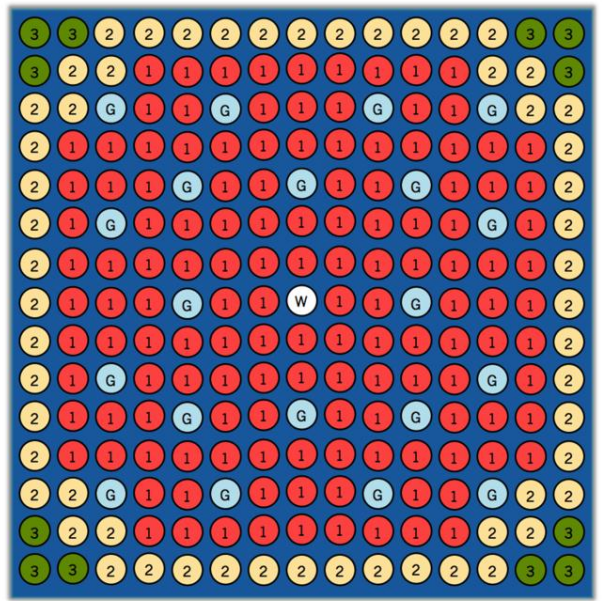

Fig. 8. PWR $15 \times 15$ MOX fuel assembly design.

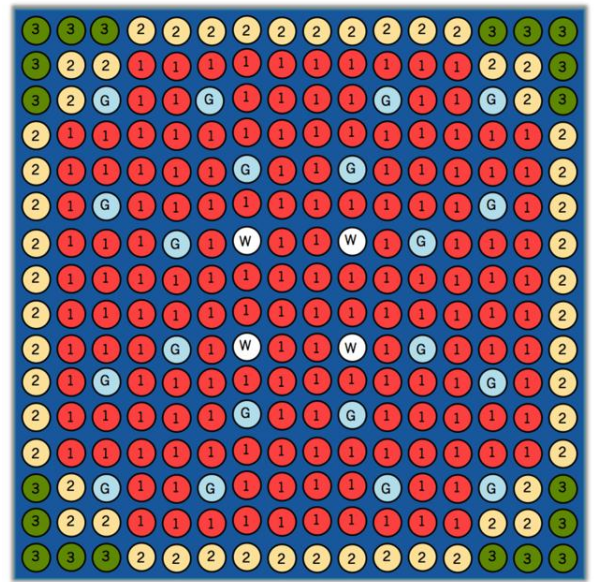

Fig. 9. PWR $16 \times 16$ MOX fuel assembly design.

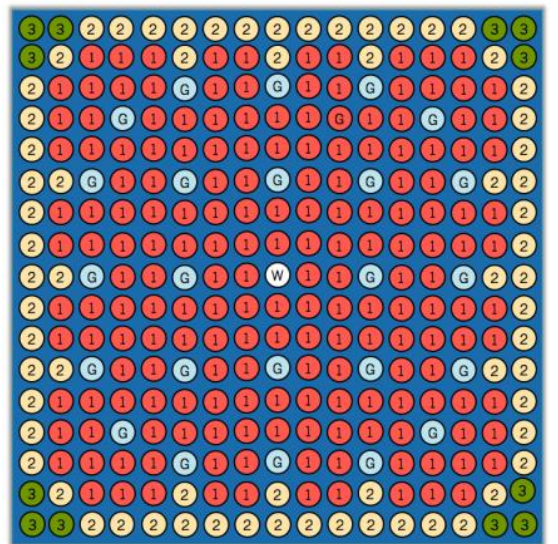

Fig. 10. PWR $17 \times 17$ MOX fuel assembly designs. 


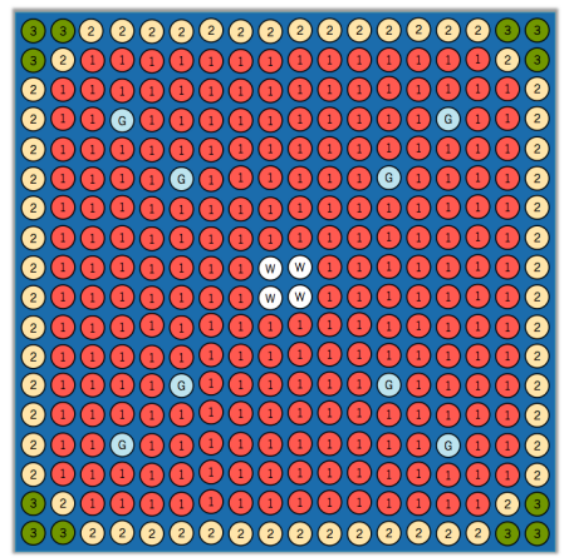

Fig 11. PWR $18 \times 18$ MOX fuel assembly design.

The variations in zoning patterns and number of zones can be seen among the illustrated designs (e.g., there can be twice as many different enrichment zones in BWR assemblies compared to PWR assemblies). Both PWR and BWR patterns were averaged to fit a common four-zone pattern as follows: (a) the corner zone includes the corner fuel rod and its two nearest neighboring rods; (b) the edge zone includes all rods at the outer edge of the assembly except for those included in the corner zones; (c) the inside edge zone includes the first layer of fuel rods neighboring the corner and the edge zone rods; and (d) the inner zone includes all fuel rods surrounded by the inside edge zone fuel pins.

If the $\mathrm{Pu}_{\text {fiss }}$ distributions for the assemblies shown in Figures 5 through 11 are averaged arithmetically to fit into the four-zone pattern and $\mathrm{Pu}_{\text {fiss }}$ ratios of each zone to the inner zone are calculated, a pattern can be seen as listed in Table 1. Significant differences in zone ratios are observed between the PWR and BWR assembly types. Although a dependency is also observed based on the specific assembly design, it is not possible to draw conclusions about this dependency with the limited number of available assembly designs. A generalized reactor type dependent pattern is shown in Table 2.

Table 1. Pufiss zone ratios (relative to the inner zone) based on reviewed MOX assembly designs

\begin{tabular}{clcccc}
\hline Reactor type & $\begin{array}{c}\text { Assembly } \\
\text { design }\end{array}$ & Corner zone ratio & Edge zone ratio & $\begin{array}{c}\text { Inside edge zone } \\
\text { ratio }\end{array}$ & Inner zone ratio \\
\hline \multirow{5}{*}{ PWR } & $17 \times 17$ & 0.45 & 0.63 & 0.90 & 1.0 \\
& $16 \times 16$ & 0.49 & 0.69 & 0.80 & 1.0 \\
& $16 \times 16$ & 0.48 & 0.68 & 0.80 & 1.0 \\
& $15 \times 15$ & 0.47 & 0.63 & 0.90 & 1.0 \\
BWR & $14 \times 14-\mathrm{W}$ & 0.50 & 0.69 & 0.85 & 1.0 \\
& $14 \times 14-\mathrm{W}$ & 0.53 & 0.72 & 0.84 & 1.0 \\
& Atrium $10 \times 10$ & 0.34 & 0.53 & 0.75 & 1.0 \\
& Atrium $10 \times 10$ & 0.33 & 0.50 & 0.81 & 1.0 \\
& Atrium $10 \times 10$ & 0.34 & 0.52 & 0.84 & 1.0 \\
& $9 \times 9-9$ & 0.42 & 0.69 & 0.94 & 1.0 \\
\hline
\end{tabular}

Table 2. Generalized Pufiss zone ratios (relative to the inner zone) based on reactor type

\begin{tabular}{cccc}
\hline Reactor type & Corner zone ratio & Edge zone ratio & Inside edge rod ratio \\
\hline PWR & 0.50 & 0.68 & 0.90 \\
BWR & 0.30 & 0.50 & 0.75 \\
\hline
\end{tabular}


Although there are assembly designs with rods having different plutonium vectors, the differences in plutonium vectors are typically small. Therefore, every assembly design used in the ORIGEN library generation is assumed to have a uniform plutonium vector across all zones.

The $\mathrm{Pu}_{\text {fiss }}$ content of a zone can be calculated relative to the inner zone. The inner zone fissile plutonium percent $\left(\mathrm{Pu} \mathrm{fins}_{\mathrm{fis}}^{\mathrm{inn}}\right)$ is calculated as shown in Eq. 3, for a given assembly average total plutonium weight percent $\left(\mathrm{Pu}_{\text {total }}^{\text {average }}\right)$ and plutonium vector.

$$
\mathrm{Pu}_{\text {fiss }}^{\text {inner }}=\mathrm{R}_{\text {fiss }} \times \frac{\mathrm{Pu}_{\text {total }}^{\text {average }} \times \mathrm{N}_{\text {total }}}{\mathrm{N}_{\text {inner }}+\mathrm{R}_{\text {inside edge }} \mathrm{N}_{\text {inside edge }}+\mathrm{R}_{\text {edge }} \mathrm{N}_{\text {edge }}+\mathrm{R}_{\text {corner }} \mathrm{N}_{\text {corner }}}
$$

Where

$$
\begin{gathered}
\mathrm{R}_{\mathrm{z}}=\frac{\mathrm{Pu}_{\text {fiss }}^{\mathrm{Z}}}{\mathrm{Pu}_{\text {fiss }}^{\text {inner }}} \quad \text { where } \mathrm{z}=\text { edge, corner, inside edge } \\
\mathrm{R}_{\text {fiss }}=\frac{{ }^{239} \mathrm{Pu}+{ }^{241} \mathrm{Pu}}{\mathrm{Pu}_{\text {tot }}} \\
\text { and } \mathrm{N}=\text { Number of Rods }
\end{gathered}
$$

The total plutonium enrichment for each zone can be calculated from Eq. 4.

$$
\mathrm{Pu}_{\mathrm{tot}}^{\mathrm{i}}=\frac{\mathrm{Pu}_{\mathrm{fiss}}^{\mathrm{i}}}{\mathrm{R}_{\mathrm{fiss}}} \text { where } \mathrm{i}=\text { inner, edge, corner, inside edge }
$$

\subsection{Cross Section Interpolation Parameters}

The interpolation grid used to upgrade the ORIGEN MOX libraries is similar to that previously used (Gauld, 2003) but is adapted for the current task. For every combination of the five plutonium vectors shown in Table 3 (with three $\mathrm{Pu}_{\text {total }}^{\text {average }}$ enrichments of $4 \%, 7 \%$, and $10 \%$ ) a separate ORIGEN MOX library is created. Each ORIGEN MOX library contains cross section data for 25 equally spaced depletion points, covering burnups ranging from 0 to $72 \mathrm{GWd} / \mathrm{tHM}$.

\begin{tabular}{|c|c|c|c|c|c|}
\hline $\mathrm{Pu}$ isotope & $50 \%$ set & $55 \%$ set & $60 \%$ set & $65 \%$ set & $70 \%$ set \\
\hline${ }^{238} \mathrm{Pu}$ & 3.175 & 2.255 & 1.563 & 1.099 & 0.864 \\
\hline${ }^{239} \mathrm{Pu}$ & 50 & 55 & 60 & 65 & 70 \\
\hline${ }^{240} \mathrm{Pu}$ & 27.825 & 27.012 & 25.634 & 23.689 & 21.177 \\
\hline${ }^{241} \mathrm{Pu}$ & 9.619 & 8.458 & 7.389 & 6.414 & 5.533 \\
\hline${ }^{242} \mathrm{Pu}$ & 9.381 & 7.275 & 5.414 & 3.798 & 2.426 \\
\hline${ }^{241} \mathrm{Am}$ & 0.1595 & 0.1405 & 0.123 & 0.1071 & 0.0928 \\
\hline
\end{tabular}

In addition to the 15 ORIGEN libraries for each PWR assembly type, BWR MOX libraries are also created with four different coolant densities $\left(0.2,0.4,0.6\right.$ and $\left.0.8 \mathrm{~g} / \mathrm{cm}^{3}\right)$ for each of the 15 combinations of plutonium vectors and enrichments, leading to a total of 60 libraries for each BWR MOX assembly type.

Table 3 Plutonium isotopic vectors* used in MOX library generation

*Isotopic vectors are in wt \% with respect to total plutonium content

\section{ORIGEN Library Verification and Validation}

The generated ORIGEN MOX libraries can easily be verified by comparing the assembly-averaged isotopic distributions calculated by detailed TRITON models to the isotopic distributions calculated by using the ORIGEN libraries in ORIGEN standalone simulations. By comparing isotopic distributions at the interpolation grid points, consistency in the library generation process and tabulations of the libraries can be verified.

On the other hand, the validation of the ORIGEN MOX libraries is a very difficult task. Since the interpolation process generates assembly-averaged cross sections, a consistent validation can only be performed if assembly-averaged isotopic measurements are available. Assuming that the flux spectrum for individual fuel pins and the assembly average spectrum are similar, ORIGEN UO libraries were validated in the past with isotopic measurements of fuel pin samples (G. Ilas et al., 2006). However, due to increased heterogeneity in the MOX assembly designs and longer neutron mean free paths, fuel pins can have considerably different flux spectra than the assemblyaverage flux spectrum (in a $\mathrm{MOX}$ assembly compared to a $\mathrm{UO}_{2}$ assembly).

Therefore, further verification of the assemblies was conducted by using the OECD Phase IV-B numerical benchmark (O'Connor, 2003) and the TRITON-calculated assembly average isotopic concentrations for the measured MALIBU samples. 


\subsection{OECD/NEA Phase IV-B MOX Benchmark}

The OECD/NEA Phase IV-B benchmark for MOX fuel (O'Connor, 2003) was developed to compare the code predictions for MOX fuel depletion and nuclear criticality safety analyses. This benchmark provides a means to compare the accuracy of the ORIGEN libraries and interpolation procedure against results obtained with well-recognized lattice physics codes for a PWR $17 \times 17 \mathrm{MOX}$ assembly.

The $17 \times 17$ PWR MOX fuel assembly model used for the benchmark is illustrated in Figure 12 . The MOX assembly has three zones with $\mathrm{Pu}_{\text {tot }}$ contents ranging from 4.9 to $8.8 \mathrm{wt} \%$. The same plutonium isotopic vector, containing $54.7 \mathrm{wt} \%{ }^{239} \mathrm{Pu}$ and $9.5 \mathrm{wt} \%{ }^{241} \mathrm{Pu}$, is used in all fuel zones. Uranium is depleted, with an enrichment of $0.25 \mathrm{wt} \%{ }^{235} \mathrm{U}$ in all fuel pins. Since the ORIGEN calculations only employ assembly-average $\mathrm{Pu}_{\text {tot }}, 8 \% \mathrm{Pu}_{\text {tot }}$ is used in these calculations.
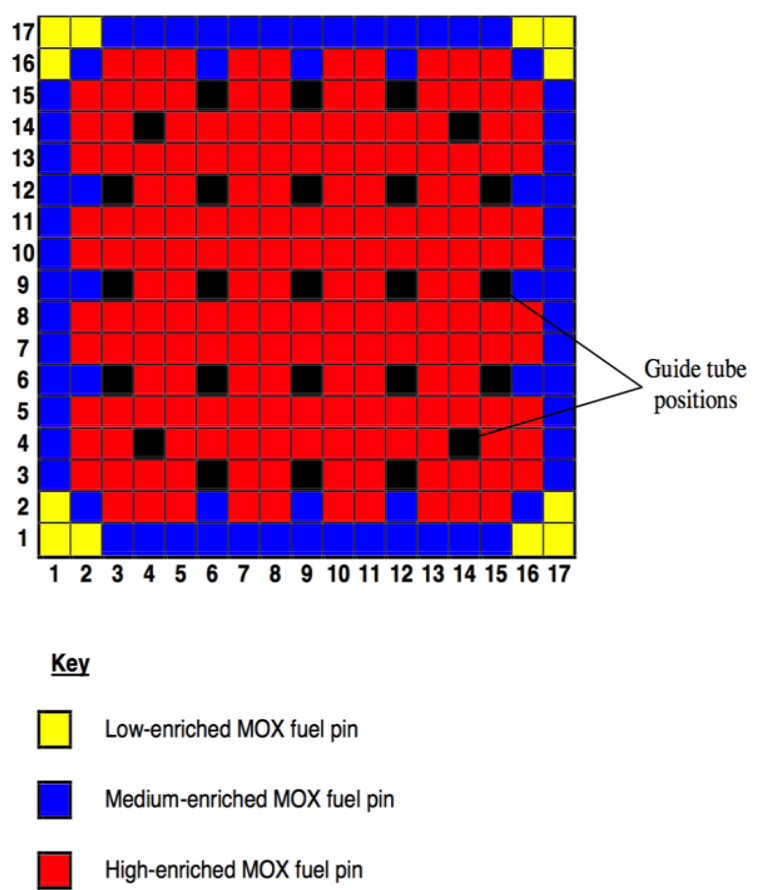

Fig. 12. MOX assembly $17 \times 17$ design specification in the OECD/NEA Phase IV-B benchmark (O'Connor, 2003).

The assembly-averaged nuclide compositions are compared to the other code results for a burnup of 48 GWd/tHM after a 5-year cooling time. For comparisons shown in the current study, the reference results for this benchmark (isotopic concentrations) were calculated as the simple mean and corresponding standard deviation of all submitted results. Figure 13 compares the ORIGEN results obtained using the $17 \times 17$ MOX library and the reference results based on results contributed by the benchmark participants. The ORIGEN results are in good agreement with the benchmark results from other participants. The deviations in the ORIGEN results are generally lower than or comparable to the standard deviation of all submitted results, with the exception of ${ }^{242} \mathrm{Am}$.

Comparisons of the ORIGEN results with the benchmark reference results provide confidence that ORIGEN calculations using the generated ORIGEN libraries can predict MOX isotopic distributions at accuracies comparable to those obtained by other rigorous physics codes. The major advantage of the ORIGEN calculations over those performed with lattice physics codes is the use of pre-generated cross section libraries, which enables very fast calculations (several seconds). The drawback of using ORIGEN is that the cross sections are developed based on typical assembly designs, fuel rod configurations, and reactor operating conditions rather than the exact configuration and conditions of the fuel assembly being analyzed. 


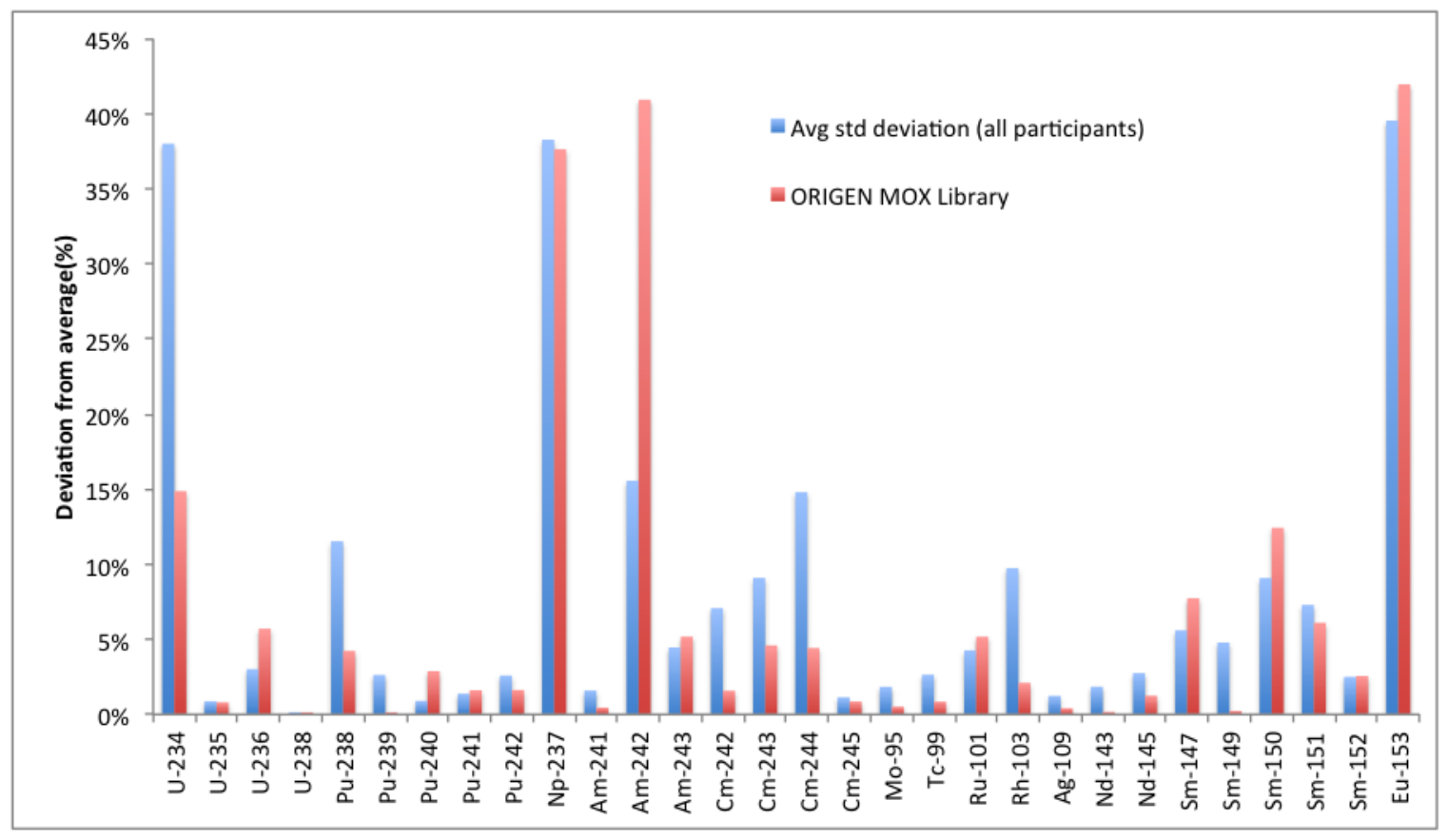

Fig. 13. OECD Phase IV-B benchmark isotopic comparisons.

\subsection{MALIBU Program Benchmark}

Validation of the detailed SCALE/TRITON depletion calculations for the MOX fuel rods measured under the MALIBU program was discussed in Section 3 of this paper. However, it is not possible to consistently compare the results of the ORIGEN calculations that use the MOX libraries and the measurements, because the MOX libraries are developed using cross sections for the assembly average and are not applicable to calculations for specific fuel rods. To provide additional verification of the MOX library performance, assembly-averaged nuclide compositions from ORIGEN were compared to assembly-averaged compositions calculated by TRITON for a detailed, heterogeneous fuel assembly design and an assembly burnup that correspond to the Gundremmingen GRM1 and Göesgen GGM1 MOX samples. Each calculation used the same assembly-average burnup, which was determined based on the concentration of ${ }^{148} \mathrm{Nd}$, which is a fission product widely used as a burnup monitor.

Comparison of assembly average nuclide concentrations for the Gundremmingen BWR assembly with a burnup of $\sim 67 \mathrm{GWd} / \mathrm{tHM}$ is presented in Fig. 14. Similarly, comparison of assembly average nuclide concentrations for the Göesgen PWR assembly with a burnup of $\sim 62 \mathrm{GWd} / \mathrm{tHM}$ is presented in Fig. 15.

Although the Göesgen assembly fuel pattern is very similar to the generalized four-zone pattern used in the generation of MOX libraries, the Gundremmingen fuel design employs a six-zone pattern with slightly higher ${ }^{235} \mathrm{U}$ enrichment. The zone ratios for both assembly designs are also different than the values in Table 2 that were used in generation of the ORIGEN libraries.

Although the effect of increased heterogeneity and deviation from the zone ratios are relatively more evident in the Gundremmingen isotopic comparisons, good agreement is observed in major actinide concentrations between the assembly-averaged TRITON and ORIGEN results in Fig. 14. The relative differences in major actinides are around $2 \%$ or less except for ${ }^{240} \mathrm{Pu}(6 \%)$. Minor actinides and fission products, ${ }^{149} \mathrm{Sm}(14 \%),{ }^{134} \mathrm{Cs}(8 \%),{ }^{244} \mathrm{Cm}(7 \%),{ }^{241} \mathrm{Am}(5 \%),{ }^{154} \mathrm{Eu}(5 \%)$, exhibit higher differences.

Göesgen results are more consistent for all isotopes in Figure 15. Relative differences for all major and minor actinides are less than 1\% except ${ }^{237} \mathrm{~Np}(3 \%)$ and ${ }^{242} \mathrm{Cm}(5 \%)$. Relative differences are less than $2 \%$ for all fission products.

The relatively small deviations and consistency of the results for assemblies from two different reactor types show the robustness and accuracy of the ORIGEN MOX libraries even for very heterogeneous and highly burned fuel. 


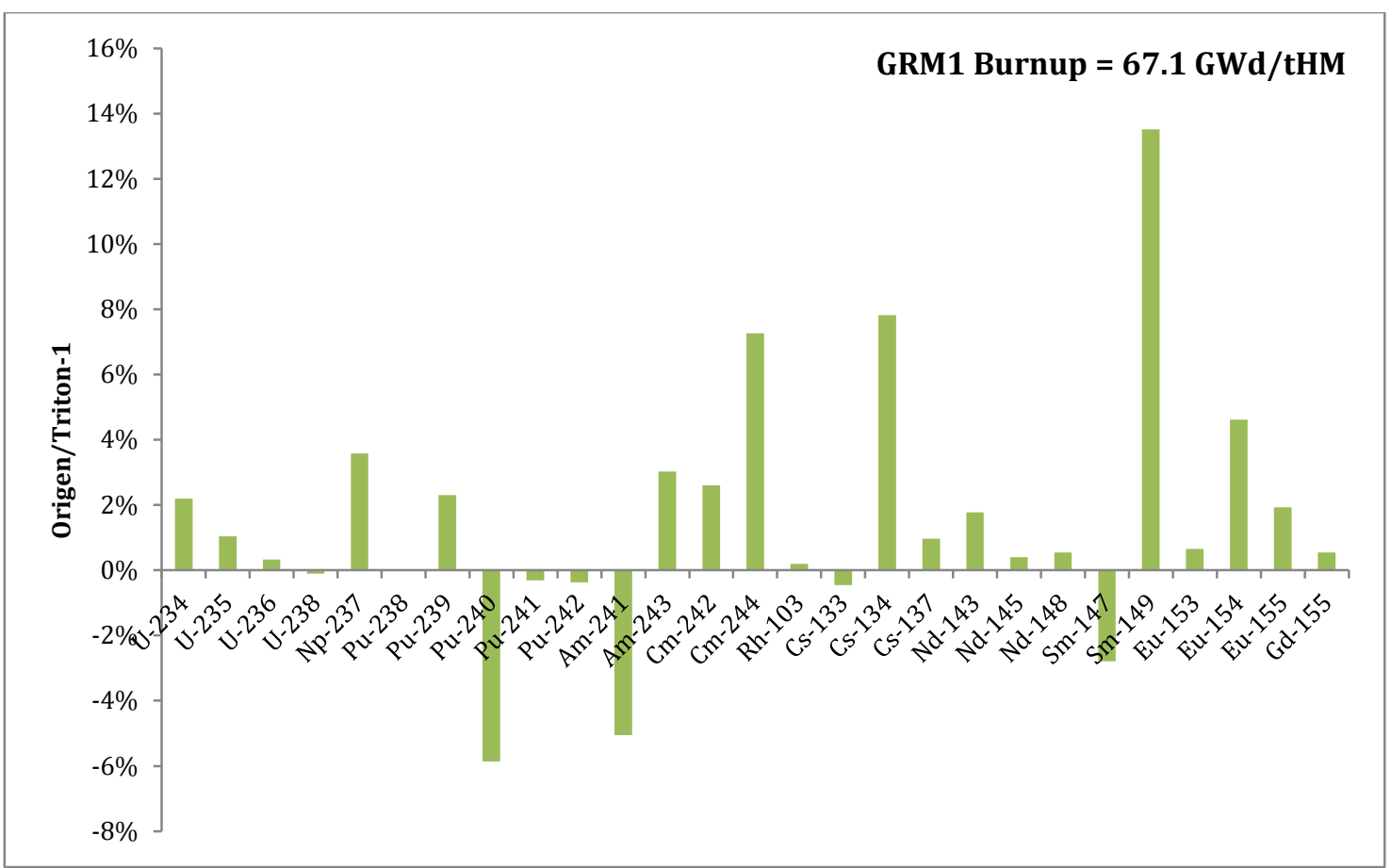

Fig. 14. Gundremmingen MOX assembly relative isotopic differences for actinides and fission products.

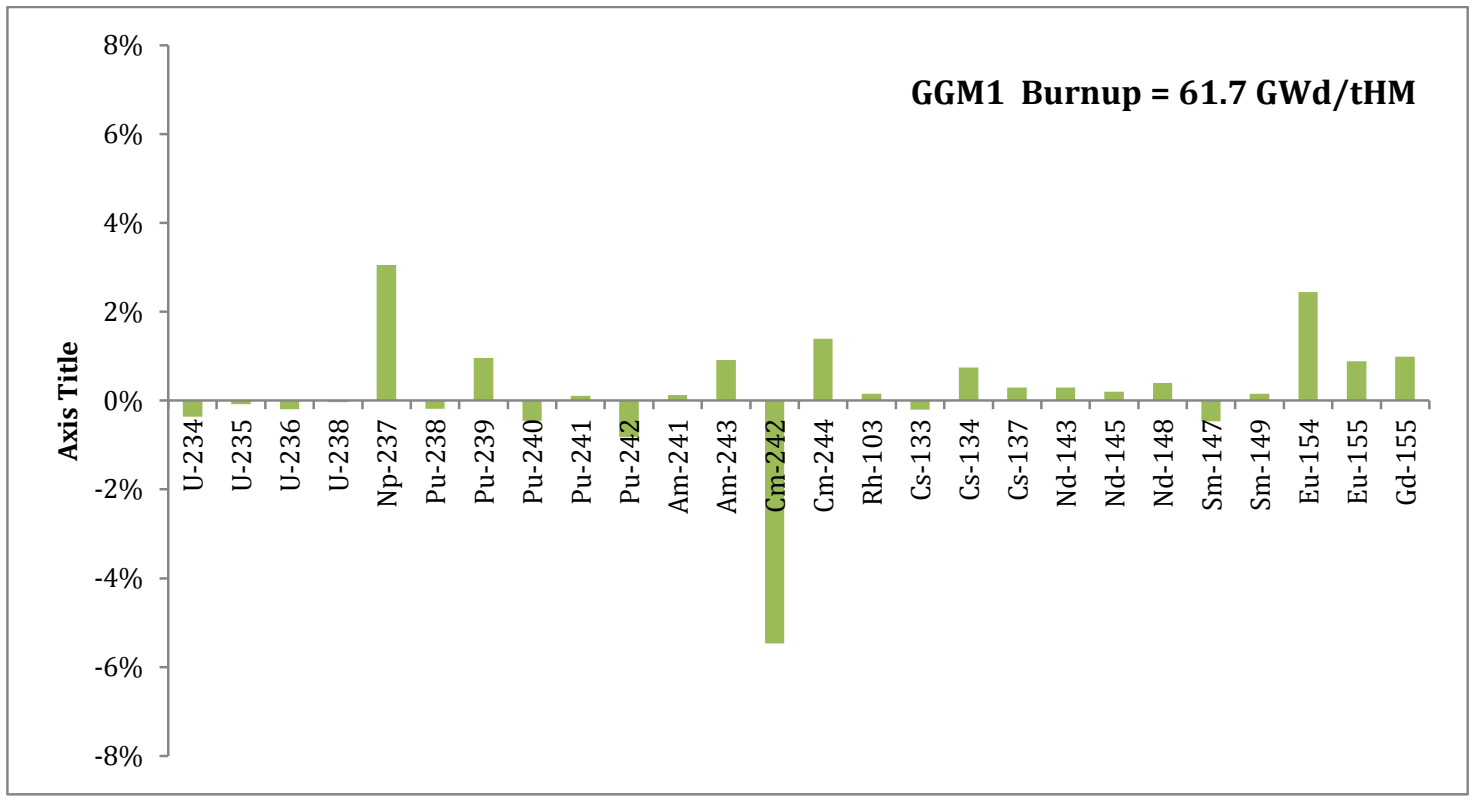

Fig. 15. Göesgen MOX assembly relative isotopic differences for actinides and fission products.

\section{Conclusions}

The ORIGEN code is recognized and used internationally for the characterization of spent nuclear fuel compositions, activities, radiation sources, and decay heat. Calculations using ORIGEN are extremely fast, but they require cross section libraries that accurately reflect the different assembly designs, enrichments, fuel configuration, and reactor operating conditions. Libraries for ORIGEN have recently been expanded and updated using modern lattice physics methods in SCALE and modern ENDF/B-VII.0 and ENDF/B-VII.1 nuclear data.

Recent integration of ORIGEN as a spent fuel analysis module in the iRAP safeguards software developed jointly by EURATOM and 
the International Atomic Energy Agency has increased the need for libraries capable of accurately simulating a wide range of $\mathrm{UO}_{2}$ and MOX assembly designs. Developing MOX libraries is particularly challenging due to the wide range of possible enrichment zone configurations that can be present in the assembly. This paper describes the development of ORIGEN libraries for MOX assemblies using typical zone patterns to generate the assembly models. The performance of these libraries for burnup analysis is demonstrated using experiment radiochemical assay data from the MALIBU international program and other verification tests.

For the analysis of NDA measurements routinely used in spent fuel safeguards, the accuracy of the simulations depends mostly on the accuracy of the neutron emitting actinide ${ }^{244} \mathrm{Cm}$, and gamma emitting fission products ${ }^{134} \mathrm{Cs}$, ${ }^{137} \mathrm{Cs}$, and ${ }^{154} \mathrm{Eu}$. The concentrations of other nuclides are also important to subcritical neutron multiplication, including the major actinides ( $\mathrm{U}$ and $\mathrm{Pu}$ ) and neutron-absorbing fission products (e.g., ${ }^{133} \mathrm{Cs},{ }^{149} \mathrm{Sm},{ }^{143} \mathrm{Nd}$ ). The validation results presented here indicated a generally good agreement for predicting ${ }^{244} \mathrm{Cm}$ (typically 10\%) and major fission products that are relevant for NDA. Additional uncertainties are reflected in the ORIGEN calculations because the MOX libraries are developed for typical assembly designs and configurations, and not for the exact design that is being evaluated. However, the results presented in this paper suggest that these uncertainties are not significant and that accuracies of better than $10 \%$ are achievable. Current testing of the iRAP software using spent fuel assembly measurements in Sweden (Gauld et al., 2015) is being used to quantitatively assess the impact of uncertainties in the detailed design and operating conditions on spent fuel verification measurements.

\section{Acknowledgement}

This work was supported under the US Department of Energy's (DOE) National Nuclear Security Administration for the International Nuclear Safeguards and Engagement Program (INSEP) as part of the DOE-Euratom cooperation agreement. The authors would like to thank Germina Ilas of Oak Ridge National Laboratory for her guidance in developing this report.

\section{References}

1. Gauld, I.C., Radulescu, G., Ilas, G., Murphy, B.D., Williams, M.L., and Wiarda, D., 2011. "Isotopic Depletion and Decay Methods and Analysis Capabilities in SCALE," Nuclear Technology 174(2), 169-195.

2. Smejkal, A. et al., 2014. "Joint Partnership - a New Software Development Paradigm," IAEA Symposium on International Safeguards: Linking Strategy, Implementation and People, Vienna.

3. Vaccaro, S., Hu, J., Svedkauskaite, J. Smejkal, A., Schwalbach, P., De Baere P., and Gauld, I.C., 2014. "A New Approach to Fork Measurements Data Analysis by RADAR-CRISP and ORIGEN Integration.” IEEE Transactions on Nuclear Science, vol. 61, issue 4, pp. 2161-2168.

4. Kinsey, R. (Ed), 1979. "ENDF/B Summary Documentation,” BNL-NCS-17541 (ENDF-201), $3^{\text {rd }}$ Edition, Brookhaven National Laboratory, New York, 1979.

5. Chadwick, M.B., Obložinský, P., Herman, M., et al., 2006. "ENDF/B-VII.0: Next Generation Evaluated Nuclear Data Library for Nuclear Science and Technology," Nuclear Data Sheets, 107, 2931-3060.

6. Boulanger, D. et al., 2004. "High burnup PWR and BWR MOX fuel performance: a review of Belgonucleaire recent experimental programs," in: CD Proceedings of the 2004 International Meeting on LWR Fuel Performance, Orlando, FL, USA.

7. Bowman, S. M., 2011. "SCALE 6: Comprehensive Nuclear Safety Analysis Code System," Nuclear Technology 174 (2), $126-148$.

8. Thorne, P.R., O'Connor, G.J., and Bowden, R.L., 2002. Problem Specification for the OECD/NEANSC Burnup Credit Benchmark Phase IV-B: Mixed Oxide (MOX) Fuels, BNFL, Risley, Warrington, Cheshire, UK.

9. Pusa, M. and Leppänen, J., 2012. "An efficient implementation of the Chebyshev rational approximation method (CRAM) for solving the burnup equations," in: Proc. PHYSOR 2012, Knoxville, TN, Apr. 15-20, 2012.

10. Isotalo, A.E., Wieselquist, W.A., 2015. "Implementation of CRAM Depletion Solver with External Feed and Improved Accuracy into ORIGEN," in: CD Proc. of the ANS MC2015- Joint International Conference on Mathematics and Computation (M\&C), Nashville, TN.

11. Chadwick, M.B., Herman, M., Obložinský, P., et al., 2011. "ENDF/B-VII.1 Nuclear Data for Science and Technology: Cross Sections, Covariances, Fission Product Yields and Decay Data," Nuclear Data Sheets, 112, 2887-2996 (2011).

12. Wilson, W.B. et al., 2002. "SOURCES 4C: a code for calculating $(\alpha, n)$, spontaneous fission, and delayed neutron sources and spectra," Biennial Topical Meeting of the American Nuclear Society/Radiation Protection and Shielding Division; Santa Fe, NM (United States); Apr 14-18, 2002; LA-UR--02-1839.

13. Sublet, J-Ch, Koning, A.J., Forrest, R.A., Kopecky, J., 2003. The JEFF-3.0/A Neutron Activation File-EAF-2003 into ENDF-6 Format, Commissariat à l'Energie Atomique, France, JEFDOC-982 (Nov. 2003). Data available from http://www.nea.fr/html/dbdata/JEFF/. 
14. Ilas, G., Gauld, I.C., and Radulescu, G., 2012. "Validation of new depletion capabilities and ENDF/B-VII data libraries in SCALE," Annals of Nuclear Energy 46 (2012) 43-55.

15. Ilas, G., Gauld, I.C., Liljenfeldt, H., 2014. "Validation of ORIGEN for LWR used fuel decay heat analysis with SCALE," Nuclear Engineering and Design, 273 (1), 58-67.

16. DeHart, M.D., and Bowman, S.M., 2011. "Reactor Physics Methods and Analysis Capabilities in SCALE," Nucl. Technol. 174(2), 196-213.

17. SCALE: A Comprehensive Modeling and Simulation Suite for Nuclear Safety Analysis and Design, ORNL/TM-2005/39, Version 6.1, Oak Ridge National Laboratory, Oak Ridge, Tennessee, June 2011. Available from Radiation Safety Information Computational Center at Oak Ridge National Laboratory as CCC-785.

18. Williams, M.L., 2011. "Resonance self-shielding methodologies in SCALE 6," Nuclear Technology 174 (2), $149-168$.

19. Matsuoka, S. and T. Ito, 2010. "Impact of Difference of Neutron Cross Section Libraries to Isotopic Concentration of Actinides," PHYSOR.

20. Gauld, I.C., 2003. MOX Cross-Section Libraries for ORIGEN-ARP, ORNL/TM-2003/2, Oak Ridge National Laboratory, Oak Ridge, Tennessee.

21. Ilas, G., I.C. Gauld, and V. Jodoin, 2006," LWR Cross Section Libraries for ORIGEN-ARP in SCALE 5.1," ANS Transactions 95 p.706.

22. "MOX Fuel Cycle Technologies for Medium and Long Term Deployment," 2000. Proceedings, IAEA, VIENNA, IAEA-CSP-3/P ISSN $1563-0153$.

23. Misu, S. et al., 2000. "Pin-By-Pin Gamma Scan Measurement on MOX and UO $\mathrm{U}_{2}$ Fuel Assemblies and Evaluation," $P H Y S O R$.

24. Yamamoto, T., 2009. Compilation of Measurement and Analysis Results of Isotopic Inventories of Spent BWR Fuels, https://www.oecd-nea.org/science/wpncs/ADSNF/reports/JNES/JNESreport2009.pdf

25. O'Connor, G.J. 2003. "Burn-up Credit Criticality Benchmark, Phase IV-B: Results and Analysis of MOX Fuel Depletion Calculations," Nuclear Science ISBN 92-64-02124-8 NEA/NSC/DOC.

26. Slavickas, A. et al., 2014. Decomposition Analysis of Void Reactivity Coefficient for Innovative and Modified BWR Assemblies, Hindawi Publishing Corporation Science and Technology of Nuclear Installations, Article ID 132737.

27. Gauld, I.C., et al., 2015, "In-Field Performance Testing of the Fork Detector for Quantitative Spent Fuel Verification," ESARDA Symposium 2015, Manchester, U.K. 